УДК 37

DOI $10.31483 / \mathrm{r}-32744$

\title{
B.3. Течиева
}

\section{СИСТЕМА ПОДГОТОВКИ СТУДЕНТОВ ПЕДАГОГИЧЕСКОГО ВУЗА К РЕАЛИЗАЦИИ ПРОГРАММ ШКОЛЬНОГО ДОПОЛНИТЕЛЬНОГО ОБРАЗОВАНИЯ ДЕТЕЙ}

Аннотация: в данной статье рассказывается о способах модернизации современного образования. Стремление общества к развитию системы дополнительного образования детей обусловлено новыми требованиями к уровню образованности человека, который определяется не столько сформированностью специальных знаний личности, сколько разносторонним ее развитием. В этой связи, возрастают меры по изменению ситуации в дополнительном образовании детей, решение которых возложено на систему педагогического образования. Однако трудности в их реализации обусловлены противоречием между потребностями социума в педагогических кадрах, способных творчески решать профессиональные задачи в сфере дополнительного образования детей, и неготовностью выпускников педагогических вузов работать в специфических условиях данной сферы. Поэтапное развитие и формирование профессионально значимых качеств личности, соответствующих специфричным ијелям и задачам деятельности в системе дополнительного образования детей, является решением данного противоречия.

Ключевые слова: дополнительное образование детей, базовые кафедры, модель подготовки специалиста, педагог дополнительного образования. 


\section{V.Z. Techieva}

\section{SYSTEM OF PREPARATION OF STUDENTS OF PEDAGOGICAL HIGHER EDUCATION INSTITUTION TO THE EXECUTION OF PROGRAMS OF CHILDREN'S ADDITIONAL EDUCATION}

Abstract: in this article the author speaks about the ways of modernization of current educational system. The desire of society to develop the system of additional education of children due to new requirements for the level of education of a person, which is determined not so much by the formation of special knowledge of the individual, as its versatile development. In this regard, measures are increasing to change the situation in additional education of children, the decision of which is entrusted to the system of pedagogical education. In this regard, measures are increasing to change the situation in additional education of children, the decision of which is entrusted to the system of pedagogical education. However, the difficulties in their implementation are due to the contradiction between the needs of society in the teaching staff, able to creatively solve professional problems in the field of additional education of children, and the unwillingness of graduates of pedagogical universities to work in the specific conditions of this sphere. Step-by-step development and formation of professionally significant qualities of the personality corresponding to the specific purposes and tasks of activity in system of additional education of children is the solution of this contradiction.

Keywords: additional education for children, basic chair, model of specialist training, teacher of additional education.

Социальные и экономические преобразования в обществе обусловили необходимость решения проблемы развития российского дополнительного образования детей, как фактора, влияющего на:

- изменение уровня социальной адаптации детей к изменяющимся условиям жизни и их успешную социализацию;

- формирование готовности к индивидуальной творческой самореализации;

- осознанное жизненное самоопределение и выбор профессии [3]. 
Основополагающие идеи модернизации дополнительного образования детей (ДОД) были изложены В.В. Путиным в предвыборной статье «Строительство справедливости. Социальная политика для России», где он предложил вернуть систему дополнительного образования детей в сферу ответственности государства - на региональный уровень, оказывая при необходимости поддержку из федерального бюджета. Такое мнение В.В. Путина обосновано произошедшим за последнее время оттоком из сферы дополнительного образования значительной части кадровых и финансовых ресурсов. Это привело к уменьшению посещаемости кружков и секций и в настоящее время охватывает только половину школьников, причем только четвертая часть из них занимается на бесплатной основе [4].

Меры, по изменению ситуации в системе дополнительного образования детей, направленные на его развитие, нашли отражение в Указе Президента Российской Федерации от 7 мая 2012 г. №599 «О мерах по реализации государственной политики в области образования и науки». Правительству Российской Федерации поручено обеспечить условия по увеличению, к 2020 году, числа детей в возрасте от 5 до 18 лет, обучающихся по программам дополнительного образования. При этом численность детей этого возраста должна достичь 70-75\% и, половина из которых обязаны обучаться за счет бюджетных ассигнований федерального бюджета. А также подготовить предложения о передаче субъектам Российской Федерации полномочий по предоставлению дополнительного образования детей, предусмотрев, при необходимости, софинансирование реализации названных полномочий за счет бюджетных ассигнований федерального бюджета [6].

Стремление общества к развитию системы дополнительного образования детей обусловлено также новыми требованиями к уровню образованности человека. Так как данная категория определяется не столько сформированностью специальных знаний личности, сколько разносторонним ее развитием, ориентирующейся в социокультурной ситуации, в традициях отечественной и мировой культуры, способной к активной социальной адаптации в обществе и самостоятельному жизненному выбору, к самообразованию и самосовершенствованию. 
Особенностью существующей системы дополнительного образования детей является ее интегративный и межведомственный характер, т.е. программы дополнительного образования детей, реализуются как в учреждениях дополнительного образования, так и общеобразовательных школах, дошкольных учреждениях, учреждениях профессионального образования, охватывают различные сферы деятельности и интересов - образование, культуру и искусство, физическую культуру и спорт. На наш взгляд, достижение показателей, отмеченных в Указе, может быть обеспечено, если реализацию программ дополнительного образования детей организовать на базе общеобразовательных учреждений в виду их заинтересованности, так как эта деятельность определена федеральными государственными стандартами дошкольного, начального, основного общего образования. Как компонент системы оно способно решать ряд проблем: удовлетворение личностно-образовательного заказа, потребности личности в новых областях знания и деятельности; поддержка ранней мотивации в сфере труда, жизненного и профессионального самоопределения; формирование способностей к жизнедеятельности. Ценность дополнительного образования детей в условиях общеобразовательной организации состоит в том, что оно усиливает вариативную составляющую общего образования, способствует практическому приложению знаний и навыков, стимулирует познавательную мотивацию обучающихся, в условиях дополнительного образования дети развивают свой творческий потенциал, навыки адаптации к современному обществу.

Однако трудности в реализации целей дополнительного образования детей, в условиях общего образования, обусловлены противоречием между потребностями социума в педагогических кадрах, способных творчески решать профессиональные задачи в сфере дополнительного образования детей, и неготовностью выпускников педагогических вузов работать в специфических условиях данной сферы.

Попытка решить данную проблему введением в 1992 году в систему российского образования специальности «педагог дополнительного образования» не увенчалась успехом, так как не получила достаточного распространения. Это 
объясняется тем, что кадровым потенциалом дополнительного образования являются специалисты различных отраслей, увлеченные творчеством, но не имеющие специальной педагогической подготовки.

Вместе с тем подготовка и переподготовка педагогических кадров для системы дополнительного образования детей предполагает организацию педагогического процесса, обеспечивающего поэтапное развитие и формирование профессионально значимых качеств личности, соответствующих специфичным целям и задачам деятельности по созданию условий для социокультурного развития ребенка.

В условиях Северо-Осетинского государственного педагогического института (СОГПИ) подготовка педагогических кадров, для системы дополнительного образования детей, представлена тремя взаимосвязанными уровнями:

- учебной, осуществляющейся в рамках реализации образовательной программы по педагогическому образованию с двумя профилями: Начальное образование и Дополнительное образование детей;

- внеучебной - освоение программ Факультета свободного развития СОГПИ;

- производственной - прохождение студенческой практики с привлечением ресурсов базовой кафедры при Республиканском дворце детского творчества.

Модель подготовки педагогов к реализации программ школьного дополнительного образования детей, состоит из целевого, теоретико-методологического, содержательного, процессуального, результативно-оценочного блоков (рис. 1). 
БЛОки

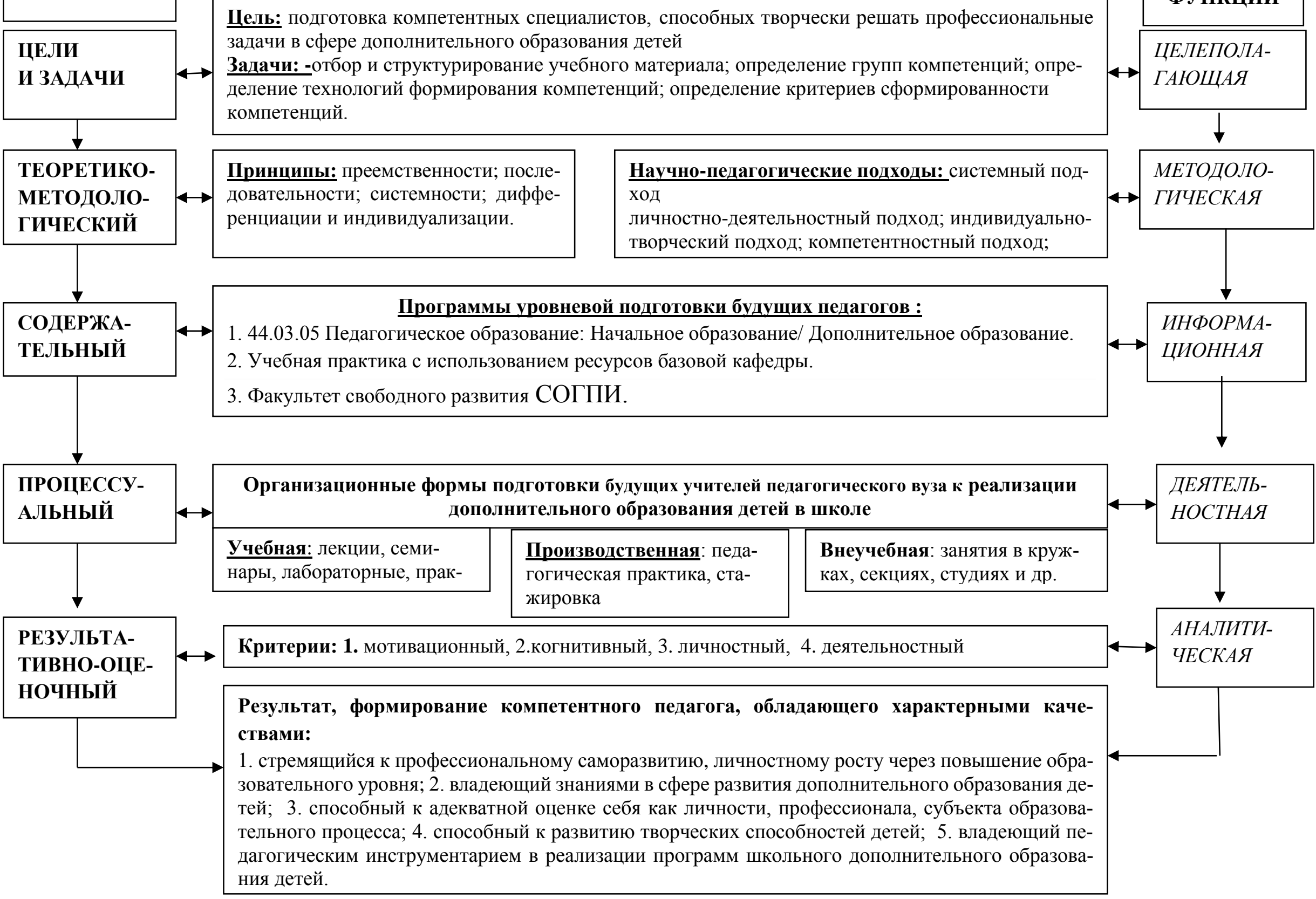

Рис.1. Модель подготовки будущих учителей педагогического вуза к реализации дополнительного образования детей в школе 
Целевой блок формирует представление о результате, достижение которого обусловлено решением ряда задач. Исходя из целевой установки подготовка компетентного специалиста, готового к творческой деятельности в условиях дополнительного образования определена педагогическими условиями, обязательными их которых являются: отбор и структурирование учебного материала; определение технологий формирования компетенций; определение критериев сформированности компетенций.

Подготовка будущих педагогов дополнительного образования опирается на ряде методологических подходах: системном, личностно-деятельностном, индивидуально-творческом, компетентностном.

Системный подход является одной из граней научного познания педагогической действительности, благодаря принципам которого обеспечивается «определенная совокупность взаимосвязанных средств, методов и процессов, необходимых для создания организованного, целенаправленного и преднамеренного педагогического влияния на формирование личности с заданными качествами» [1, с. 6.].

Личностно-деятельностный подход предполагает, что в центре обучения находится сам студент - его мотивы, цели, его неповторимый психологический склад. При реализации личностно-деятельностного подхода образовательный процесс строится в соответствии с личностными особенности обучающегося, его потребностями и возможностями. Это означает, что студент должен отрефлексировать наличный, исходный, актуальный уровень знания и затем оценить свои успехи, свой личностный рост [2].

Индивидуально-творческий подход создает условия для самореализации студента, развития его творческих способностей. Именно такой подход обеспечивает профессионально-личностное становление будущего педагога, формирует способность применять его на деле в работе с детьми.

Смысл компетентностного подхода заключается в развитии у студентов способности к самостоятельному решению проблем в разных видах и сферах деятельности, используя профессионально-теоретический, профессионально-практический, личностно- социальный опыт. 
В соответствии с теоретико-методологическим блоком сообразно разрабатываются образовательные программы содержательного блока, реализация которых осуществляется с применением современных педагогических технологий, в том числе интерактивных. При этом, основная деятельность ведущих кафедр института состоит в формировании фундаментальных психолого-педагогических знаний у будущих педагогов, закрепление которых традиционно осуществляется в рамках учебной и производственной практики, что не позволяет в достаточной степени ориентировать выпускников на исполнение трудовых функций, установленных профессиональным стандартом педагога. В этой связи, появление в модели базовой кафедры с участием Республиканского дворца детского творчества позволяет осуществить адресную помощь будущим педагогам в практическом осмыслении учебной, методической, научно-исследовательской, воспитательной, внеучебной деятельности, с привлечением к этому высококвалифицированных специалистов - практиков РДДТ [5].

Деятельность сотрудников базовой кафедры осуществляется по таким основным направлениям как:

- организационно-методическая работа;

- организация практической подготовки студентов;

- учебно-методическая работа;

- научно-исследовательская работа;

- воспитательная работа.

Таким образом, реализация представленной модели направлена на формирование у выпускника следующих характерных профессионально-личностных качеств:

- стремящийся к профессиональному саморазвитию, личностному росту через повышение образовательного уровня;

- владеющий знаниями в сфере развития дополнительного образования детей;

- способный к адекватной оценке себя как личности, профессионала, субъекта образовательного процесса;

- способный к развитию творческих способностей детей; 
- владеющий педагогическим инструментарием в реализации программ школьного дополнительного образования детей.

Исходя из профессионально-личностных качеств вытекает, что выпускник, освоивший образовательную программу по профилю «Начальное образование и дополнительное образование детей» должен быть готов к развитию талантов и способностей детей, включая их в художественную, техническую, спортивную деятельность. Способен к комплектованию состава творческих объединений, к ведению образовательной деятельности, обеспечивая обоснованный выбор педагогического инструментария для взаимодействия. Готов к разработке авторских программ и нести ответственность за качество их реализации. Способен оказывать консультативную помощь родителям в вопросах определения потребностей и интересов их ребенка в дополнительном образовании.

\section{Сиисок литературы}

1. Беспалько В.П. Слагаемые педагогической технологии. - М.: Педагогика, 1989. - $182 \mathrm{c}$.

2. Зимняя И.А. Педагогическая психология: учебник для вузов. - Изд. 2, доп., испр. и перераб. - М.: Логос, 2000. - 384 с.

3. Концепции развития дополнительного образования детей на период до 2020 года. Распоряжение Правительства РФ от 04.09.2014 N 1726. [Электронный pecypc]. - Режим доступа: http://static.government.ru/media/files/ipA1NW42XOA.pdf (дата обращения: 10.05.2019).

4. Путин В.В. Строительство справедливости. Социальная политика для России // Комсомольская правда. 13.02.2012. [Электронный ресурс]. - Режим доступа: http://www.kp.ru/daily/25833/2807793/ (дата обращения: 10.05.2019).

5. Течиева В.3. Базовые кафедры педагогического вуза в подготовке практико-ориентированного учителя / Научно-теоретический журнал «Экономические и гуманитарные исследования регионов» №5 - 2017. - С. 48-52.

6. Указ Президента Российской Федерации от 7 мая 2012 г. №599 «О мерах по реализации государственной политики в области образования и науки». 
[Электронный pecypc]. - Режим доступа: http://base.garant.ru/70170946/ (дата обращения: 10.05.2019).

\section{References}

1. Bespal'ko, V. P. (1989). Slagaemye pedagogicheskoi tekhnologii., 182. M.: Pedagogika.

2. Zimniaia, I. A. (2000). Pedagogicheskaia psikhologiia., 384. M.: Logos.

3. Kontseptsii razvitiia dopolnitel'nogo obrazovaniia detei na period do 2020 goda. Rasporiazhenie Pravitel'stva RF ot 04.09.2014 N 1726. Retrieved from http://static.government.ru/media/files/ipA1NW42-XOA.pdf

4. Putin, V. V. Stroitel'stvo spravedlivosti. Sotsial'naia politika dlia Rossii. Komsomol'skaia pravda. 13.02.2012. Retrieved from http://www.kp.ru/daily/25833/2807$793 /$

5. Techieva, V. Z. Bazovye kafedry pedagogicheskogo vuza v podgotovke praktiko-orientirovannogo uchitelia., 48-52.

6. Ukaz Prezidenta Rossiiskoi Federatsii ot 7 maia 2012 g. 599 "O merakh po realizatsii gosudarstvennoi politiki v oblasti obrazovaniia i nauki". Retrieved from http://base.garant.ru/70170946/

Течиева Виктория Заурбековна - канд. пед. наук, дочент ГБОУ ВО «Северо-Осетинский государственный педагогический институт», Россия, Владикавказ.

Techieva Viktoria Zaurbekova - candidate of pedagogical sciences. assistant professor at the SBEI of HE "North Ossetian State Pedagogical Institute", Russia, Vladikavkaz. 